\title{
Modern Trends of Nitrogen Diagnostics for Purposes of Crop Fertilization
}

\author{
Afanasev RA* and Litvinskiy VA \\ Pryanishnikov Institute of Agro chemistry, Russia \\ *Corresponding author: Afanasev RA, Pryanishnikov Institute of Agro chemistry, Russia
}

Submission: 㭰 April 06, 2018; Published: 監 April 20, 2018

\section{Introduction}

Diagnosis of mineral, primarily nitrogen, plant nutrition has long been a priority in agrochemical science and agricultural practice. To determine the requirements of crops in basic nutrients such as phosphorus and potassium, soil diagnostics (the determination of the mobile forms of these elements in soils) was widely used, on the basis of which the doses of the corresponding types and forms of fertilizers were calculated. Soil diagnostics were also used to identify the need for plants in nitrogen fertilizers, mainly in the presowing period or at the beginning of the active vegetation of crops.

But unlike the content of mobile forms of phosphorus and potassium, which is characterized by relative stability even for several years, the content of nitrogen compounds available for plant nutrition in the soil requires constant monitoring during each growing season because of the instability in time, the dynamism of this indicator, with one side, and the special requirements of plants to nitrogen practically throughout their entire vegetation, on the other. And if the sufficient supply of plants with phosphorus and potassium can be achieved with the advance application of fertilizers, then the situation with nitrogen is somewhat different.

As a rule, nitrogen fertilizers applied to the soil in the early spring just prior to the sowing of spring crops or as surface application at the beginning of the growing season of winter cereals, focusing on agrochemical soil survey data, including rapid diagnostics. During the critical vegetation periods (tilleringbranching, shooting-stooling, ear formation-blooming, formation of seeds, other reproductive organs) vegetative fertilizing with nitrogen fertilizers is carried out to optimize nitrogen nutrition of cereals and other agricultural crops according to the results of chemical plant diagnostics of leaves and stem.

In recent decades, more and more important, especially abroad, along with chemical, acquire physical, namely photometric, methods for diagnosing nitrogen nutrition of crops. This method based on the connection of the intensity of green coloring of plants with their supply of nitrogen. The photo detectors of diagnostic devices register either the concentration of chlorophyll in the indicator organs of plants, or the intensity of its fluorescence.
The demand for certain crops in nitrogen fertilizers at a certain period of their vegetation is calculated as a result of thematic processing of data obtained by contact or remote determination of aforementioned indicators. The most widespread indicator used for such calculation is so-called normalized difference vegetation index (NDVI), representing the ratio of the difference between the values of the infrared and red spectra of electromagnetic reflection of solar or artificial light from plants to their sum. The detectors of electromagnetic radiation by plant biomass are photometric devices of various designs used as portable (hand) devices ("YARA" and "Crop Circle" manufactured in Europe, CCM-200, CCM-1000 and «Green Seecer» manufactured in USA, one and two-beamed "Spectrolyuks" manufactured in Russia) or as N-sensors mounted on equipment for fertilizers applying («YARA», «ALS») or as multifunctional photometers, mounted on air or space vehicles.

From the types of remote sensing most noteworthy are photography and TV shooting in $0.3-1.1 \mu \mathrm{m}$ diapason, spectral indication in UV/VIS and NIR diapasons $(0.33 .0 \mu \mathrm{m})$, IR diapason (3 $300 \mu \mathrm{m})$, microwave diapason $(0.310 .0 \mathrm{~cm})$ and radio waves diapason $(1070 \mathrm{~cm})$. Information obtained in the different diapasons (UV, VIS, NIR, IR and radio waves) by different means is used by different branches of the national economy. According to our previous research, both terrestrial and aerospace surveys can be successfully applied for the diagnosis of nitrogen nutrition of plants. However, despite significant advantages over traditional chemical diagnostics, both terrestrial and space indications of the availability of agricultural crops with nitrogen have certain limitations: terrestrial-by the scale of coverage, aerospace-by time parameters.

At the same time, it was shown that the use of low-flying aircraft, in particular helicopters, is most suitable for photometric inspection of crops, although its application has a significant limitation - at the cost of diagnostic work. In this regard, the most promising is the use for rapid diagnosis of nitrogen nutrition plants an unmanned aerial vehicle (UAV) equipped with appropriate photometric instruments. Conducted in Russia research proved the possibility of using the UAVs for agro diagnostics. 
Creative Commons Attribution 4.0 International License

For possible submissions Click Here

Submit Article MCDA Moderm concepent

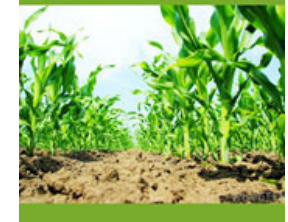

Modern Concepts \& Developments in Agronomy

\section{Benefits of Publishing with us}

- High-level peer review and editorial services

- Freely accessible online immediately upon publication

- Authors retain the copyright to their work

- Licensing it under a Creative Commons license

- Visibility through different online platforms 